\title{
Efeito da aplicação de água residuária de suinocultura no solo e na qualidade dos seus lixiviados
}

\section{Effect of swine wastewater in soil and quality of its leachate}

\author{
Hugo Renan Bolzani \\ Tecnólogo em Gerenciamento Ambiental pela Universidade Tecnológica Federal do Paraná (UTFPR) - Campo Mourão (PR), Brasil. Mestre em Engenharia \\ Urbana pela Universidade Estadual de Maringá (UEM) - Maringá (PR), Brasil.
}

\section{Darlene Lopes do Amaral Oliveira}

Química pela Universidade Estadual Paulista Júlio de Mesquita Filho (UNESP) - Araraquara (SP), Brasil. Mestre em Agronomia pela UEM - Maringá (PR), Brasil. Professora do Departamento de Tecnologia e Engenharia Ambiental da UTFPR - Campo Mourão (PR), Brasil.

\section{Sandro Rogério Lautenschlager}

Engenheiro Civil pela UEM. Mestre e Doutor em Engenharia Hidráulica e Sanitária pela Universidade de São Paulo (USP) - São Paulo (SP), Brasil. Professor Adjunto do Departamento de Engenharia Civil da UEM - Maringá (PR), Brasil.

\section{Resumo}

Este trabalho avalia o comportamento da água residuária de suinocultura, quanto aos seus efeitos no solo e na qualidade dos seus lixiviados. Na incubação do

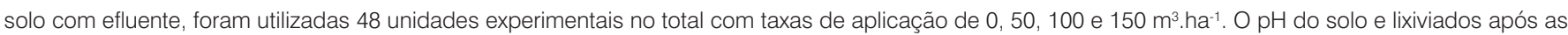
diferentes taxas de aplicação permaneceu ácido e os valores de amônia nos argissolos apresentaram valores menores do que no solo testemunha enquanto que nos nitossolos houve aumento em função das taxas de aplicação. A capacidade de troca catiônica aumentou com maior intensidade nos argissolos. A relação carbono/nitrogênio foi baixa evidenciando uma mineralização rápida dos resíduos orgânicos. Os valores de nitrato no primeiro lixiviado e de fósforo nos nitossolos foram maiores do que nos argissolos, em função da taxa de aplicação.

Palavras-chave: lixiviado; efluente de suinocultura; nitossolo; argissolo.

\section{Abstract}

This study evaluates the behavior of swine effluent for their effects on soil and the quality of the leachate. In the incubation of soil with effluent were used 48 units in total with experimental application rates of 0,50, 100 and $150 \mathrm{~m}^{3}$.ha-1. The soil $\mathrm{pH}$ and leached after the application of different rates remained acid and the values of ammonia in the argisols (Pax; Ultisol) showed minor values than in the witness soil while at the nitosols the values increased due to the application rates. The cation exchange capacity increased with greater intensity in argisols. The carbon/nitrogen relation was low showing a rapid mineralization of organic waste. The values of nitrate in leachate and the first of the phosphorus nitosol were higher than in the argisols, depending on the rate of application.

Keywords: leachate; swine effluent; nitosol; argisol.

\section{Introdução}

A utilização de efluente de suinocultura nos solos agrícolas é recomendável, porém requer uma combinação harmoniosa dos princípios da Ciência do Solo, Saúde Pública e Hidrologia. Segundo Konzen (1983), estes efluentes são constituídos por fezes, urina, água desperdiçada pelos bebedouros e de higienização, resíduos de ração, pelos, poeiras e outros materiais decorrentes do processo criatório.

Estudos efetuados em diversos países demonstraram que a produtividade agrícola aumenta significativamente em áreas fertirrigadas com águas residuárias, desde que estas sejam adequadamente manejadas. Apesar das vantagens do uso da água residuária na agricultura, sua utilização de maneira inadequada pode trazer alguns riscos como: contaminação microbiológica dos produtos agrícolas e do lençol freático, acumulação de elementos tóxicos, desequilíbrio de nutrientes, salinização e impermeabilização do solo (SEGANFREDO, 2000).

Nutrientes com alta mobilidade no solo atingem o volume de solo explorado pelas raízes rapidamente, porém se perdem facilmente por lixiviação e, se manejados incorretamente, podem contaminar as águas subterrâneas. A mobilidade vertical 
dos nutrientes no solo é afetada por fatores físicos e químicos. Os principais atributos físicos, segundo Prevedello (1996), incluem a distribuição relativa do tamanho de poros e seus graus de saturação com água e a quantidade de água que percola no perfil, a qual depende da quantidade e intensidade das chuvas e da capacidade de retenção de água pelo solo. Os principais aspectos químicos são: a concentração da solução do solo, o pH, a capacidade de troca de cátions, as reações de dissolução/precipitação e as trocas iônicas entre os nutrientes que estão na solução com aqueles da fase sólida durante o processo de descida.

Durante a incidência das chuvas quando o solo ainda não atingiu a condição de saturação e quando a taxa de infiltração supera a de precipitação, a água se move em direção aos lençóis freáticos, representando o processo de lixiviação, sendo este um fator importante de perda de nutrientes. Os nutrientes perdidos, deste modo, pelos ecossistemas, tendem a ser levados aos rios e lagos entrando assim em outro sistema (ciclo hidrológico). Com isso, o entendimento das modificações dos parâmetros químicos (contidos no efluente de suinocultura) no solo e o manejo dos mesmos são fatores essenciais para a sustentabilidade da irrigação com efluente.

Apesar de já existirem muitos resultados experimentais, no que diz respeito ao aproveitamento de efluente de suinocultura no solo, estes não dispõem de informações suficientes para assegurar o seu uso no que diz respeito às questões ambientais. Dentro deste contexto, este trabalho teve como objetivo avaliar o comportamento das águas residuárias efluente de suinocultura, quanto aos seus efeitos no solo e na qualidade dos seus lixiviados.

\section{Metodologia}

O experimento foi realizado nas dependências do laboratório de solos, da Universidade Tecnológica Federal do Paraná (UTFPR), Campus Campo Mourão, no período de novembro de 2008 a julho de 2009.

O efluente utilizado no experimento (conduzido em laboratório) foi coletado após a passagem por um biodigestor, em um empreendimento que explora economicamente a suinocultura. Posteriormente o efluente foi transportado ao laboratório onde se procedeu à caracterização química (Tabela 1) conforme as metodologias descritas no Standard Methods for Examination of Water and Wastewater (APHA, 2005). A aplicação nos solos foi realizada três vezes em intervalos de 30 dias.

Os solos estudados neste experimento pertencem ao grande grupo do latossolo vermelho distrófico com textura argilosa (argissolo) no município de Campo Mourão (PR) e outro com textura arenosa (nitossolo) do município de Cianorte (PR), coletados em camadas de 0 a $20 \mathrm{~cm}$ de profundidade em áreas não cultivadas em 20 pontos distintos dispostos em zigue-zague.

As amostras compostas obtidas foram devidamente identificadas, secas em estufa de circulação de ar a uma temperatura de $45^{\circ} \mathrm{C}$, homogeneizadas e tamisadas em peneiras $(2 \mathrm{~mm}$ de diâmetro) e na sequência procedeu-se à caracterização química e física do solo (Tabela 2) conforme metodologia preconizada pela Empresa Brasileira de Pesquisa Agropecuária (EMBRAPA) (EMBRAPA, 1999). Posteriormente as mesmas foram estocadas como terra fina seca ao ar (TFSA).

No laboratório, foi avaliada a capacidade de campo e a densidade aparente dos solos, construídas curvas de neutralização e medido o teor de umidade pelo método gravimétrico de acordo

Tabela 1 - Caracterização química do efluente de suinocultura utilizado no experimento.

\begin{tabular}{|c|c|c|c|c|c|c|c|c|c|c|c|c|c|c|}
\hline Primeira & 2,499 & 0,884 & 1,615 & 3,24 & 7,20 & 448,0 & 63,9 & 146,4 & 181,8 & 218,1 & 615,6 & 114,3 & 42,9 & - \\
\hline Segunda & 1,990 & 1,204 & 0,786 & 3,40 & 6,92 & 632,0 & 85,0 & 194,7 & 232,1 & 278,5 & 876,5 & 155,3 & 71,1 & - \\
\hline
\end{tabular}

ST: sólidos totais; SF: sólidos fixos; SV: sólidos voláteis; Cond.: condutividade; NTK: nitrogênio total Kjeldahl ; P: fósforo; $\mathrm{P}_{2} \mathrm{O}_{5}$ : pentóxido de fósforo; $\mathrm{K}$ : potássio; $\mathrm{K}_{2} \mathrm{O}$ : óxido de potássio; C.O.T: carbono orgânico total; Ca: cálcio; Mg: magnésio; DQO:demanda química de oxigênio.

Tabela 2 - Caracterização física e química dos solos utilizados no experimento.

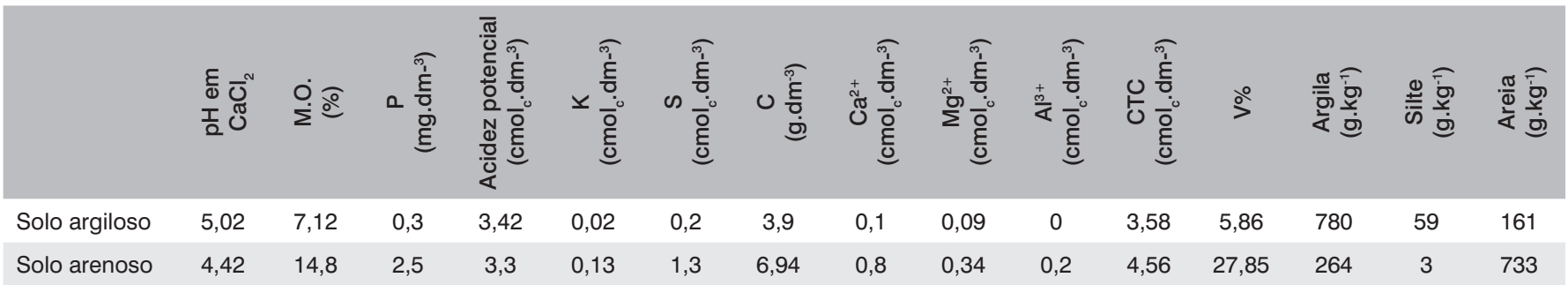

M.O.: matéria orgânica; P: fósforo; K: potássio; S: enxofre; C: carbono; $\mathrm{Ca}^{2+}$ : cálcio; $\mathrm{Mg}^{2+}$ : magnésio; $\mathrm{Al}^{3+}$ : alumínio; CTC: capacidade de troca catiônica; V\%: saturação por bases. 
com a norma NBR14283 (ABNT, 1999). A obtenção das curvas de neutralização, utilizando-se carbonato de cálcio $\left(\mathrm{CaCO}_{3}\right)$ permitiu observar a propriedade tampão de cada solo, ou seja, a resistência à variação do $\mathrm{pH}$, sendo necessárias grandes quantidades para atingir pH igual a 7,5-0,1 g e 0,15 g de $\mathrm{CaCO}_{3}$ em $50 \mathrm{~g}$ de solo seco para o nitossolo e argissolo, respectivamente. A capacidade de campo foi de 267 e $367 \mathrm{~g}$ de água por $100 \mathrm{~g}$ de solo seco enquanto que a densidade aparente foi de 0,59 e 0,80 g. $\mathrm{cm}^{-3}$ para o nitossolo e argissolo, respectivamente.

Em seguida, os solos foram incubados por um período de 40 dias com $\mathrm{CaCO}_{3}$. Os cálculos foram feitos para obtenção de saturação de bases (V\%) igual a 50. Ao nitossolo foram adicionados $510 \mathrm{mg} \cdot \mathrm{L}^{-1} \mathrm{e}$ ao argiloso $815 \mathrm{mg} . \mathrm{L}^{-1}$ de $\mathrm{CaCO}_{3}$ (pró-analise da marca VETEC). O V\% para os diferentes solos avaliados foi, portanto, para o solo argiloso 4,47 e $50 \%$ enquanto que para o solo arenoso foi de 27,63 e $50 \%$.

\section{Montagem dos protótipos contendo os tubos de percolação}

O experimento foi instalado em tubos de percolação de $25 \mathrm{~cm}$ de altura e $10 \mathrm{~cm}$ de diâmetro (garrafas PET) dispostos em uma armação de madeira (Figura 1), os quais apresentaram na base uma abertura à qual foi conectada uma mangueira flexível de $0,5 \mathrm{~cm}$ de diâmetro de forma a permitir a condução do líquido percolado através do solo para recipiente coletor. Esta abertura foi protegida por uma tela fina de plástico (sombrite) e um tecido fino de voal cortado em forma cilíndrica e adaptável á base do tubete de PET. Em seguida, foi adicionada areia grossa previamente lavada para evitar o entupimento da mangueira cristal. Sobre a areia grossa foi acomodado um litro de solo (TFSA).

\section{Tratamentos adotados}

O delineamento experimental empregado para a incubação do solo com efluente foi inteiramente casualizado, com três repetições. Os tratamentos estudados consistiram em um esquema fatorial $2 \times 4 \times 2$ para solo, doses e pH. Foram utilizadas 48 unidades

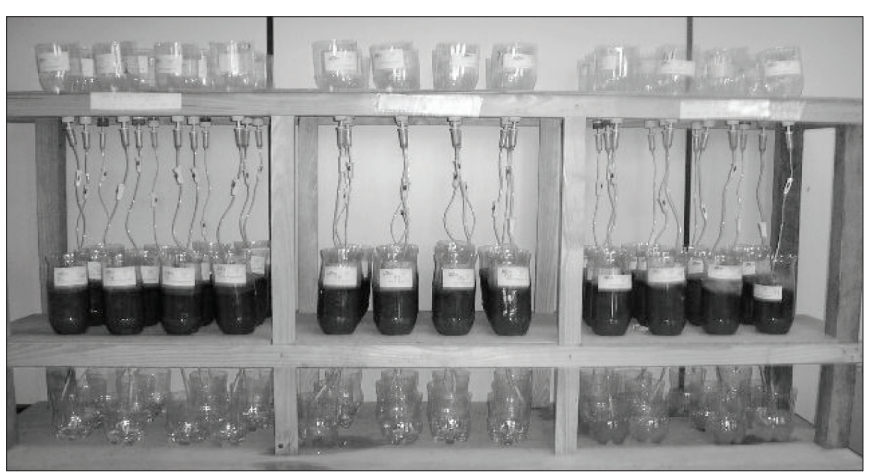

Figura 1 - Aspecto do protótipo contendo os tubos de percolação. experimentais no total. Durante o período de incubação a umidade dos solos tratados ou não com efluente foi mantida por meio de adições periódicas de água destilada.

Foram realizadas três adições do efluente aos 30, 60 e 90 dias em taxas de aplicação (TA) de 0,50, 100 e $150 \mathrm{~m}^{3}$.ha ${ }^{-1}$ nos tubetes que continham o solo. Água destilada foi adicionada juntamente com o efluente suficiente para completar o volume de 60\% da capacidade de campo. Após 120 dias de montado o protótipo, procedeu-se à passagem de água destilada pelos tubos de percolação nas quantidades correspondentes a duas vezes a capacidade de campo dos solos de estudo. A água foi adicionada lentamente para que o solo pudesse saturar.

\section{Coleta e análise dos lixiviados}

A coleta de líquido percolado obtido de cada tratamento foi feita em frascos de $500 \mathrm{~mL}$ da seguinte forma: os $500 \mathrm{~mL}$ iniciais foram considerados como primeiro lixiviado, trocaram-se os frascos e coletaram-se os próximos $500 \mathrm{~mL}$, sendo considerados o segundo lixiviado. Após a coleta, foram determinadas as concentrações de nitrato $\left(\mathrm{NO}_{3}^{-}\right)$, amônia $\left(\mathrm{NH}_{4}^{+}\right)$, matéria orgânica, $\mathrm{pH}$, fósforo (P) e demanda química de oxigênio (DQO). Essas análises também seguiram as metodologias propostas pelo Standard Methods for Examination of Water and Wastewater (APHA, 2005). Para medir os teores de $\mathrm{P} \mathrm{NO}_{3}{ }^{-} \mathrm{e} \mathrm{NH}_{4}^{+}$, foram utilizados a espectrofotometria (método da redução com ácido ascórbico) de Cataldo et al. (1975) e da metodologia do Fenato, respectivamente. Os teores de pH foram determinados por leitura direta por potenciometria e a DQO foi determinada por refluxo fechado utilizando a titulação redox dicromato de potássio em meio ácido titulado com sulfato ferroso amoniacal e ferroin como indicador.

\section{Preparo do solo após a percolação para análise}

Depois de realizada a coleta dos lixiviados, os tubos de percolação foram cortados para a retirada do solo e dispostos em sacos plásticos de parede reforçada, os quais foram por sua vez identificados e posteriormente armazenados em freezer e mantidos congelados até as determinações analíticas de nitrogênio mineral (N).

\section{Análise do nitrogênio mineral no solo}

A dinâmica do $\mathrm{N}$ no solo foi avaliada por meio da análise dos teores de $\mathrm{N}$ mineral, $\mathrm{NH}_{4}^{+}$e $\mathrm{NO}_{3}$. Para a determinação dos teores de $\mathrm{N}$ mineral do solo foram utilizadas as metodologias de extração descritas por Tedesco et al. (1995), as quais preconizam a extração do solo úmido com cloreto de potássio $(\mathrm{KCl}) 1 \mathrm{M}$ relação solo:extrator 1:10 e agitação por 1 hora. Em uma alíquota de $25 \mathrm{~mL}$ do sobrenadante determinou-se $\mathrm{NH}_{3}{ }^{+}$pelo método do Fenato (APHA, 2005) e 
em outra alíquota do extrato $\mathrm{KCl}$ foi determinado o $\mathrm{NO}_{3}{ }^{-}$por meio do método de Cataldo et al. (1975) utilizando o ácido salicilíco.

\section{Preparo e análise do solo}

Depois de realizadas as análises de $\mathrm{NO}_{3}{ }^{-}{\mathrm{e} \mathrm{NH}_{4}}_{4}$, as amostras de solo foram secas ao ar, homogeneizadas, destorroadas e passadas em peneira de $2 \mathrm{~mm}$ de malha, sendo a concentração de $\mathrm{P}$ disponível determinada com extrator Mehlich 1 por colorimetria, o carbono orgânico foi determinado pelo método de Walkley BLack e o pH em água e em KCl 1M por potenciometria (EMBRAPA, 1997). A soma de bases trocáveis e o índice de saturação por bases foram obtidos por cálculo enquanto a capacidade de troca catiônica (CTC) foi obtida pelo método da soma de bases trocáveis. $\mathrm{O} \Delta \mathrm{pH}$ foi calculado pela diferença entre o pH em água e o pH em KCl.

\section{Resultados e Discussão}

A análise dos solos, após 120 dias de incubação, mostrou que o pH permaneceu ligeiramente ácido (Tabela 3), muito embora os efluentes aplicados tenham apresentado condição alcalina, com $\mathrm{pH}$ próximo a 7,0

Observou-se que os valores de $\mathrm{pH}$ dos solos de textura arenosa decresceram em função do aumento da taxa de aplicação do efluente enquanto que nos de textura argilosa ocorreu um acréscimo ou os valores variaram pouco, apresentando um CV máximo de 3\%.

A aplicação dos fertilizantes nitrogenados possuem um efeito residual ácido em função da reação de nitrificação. Uma pesquisa realizada por Simonete (2001) evidenciou que a aplicação de efluentes de esgoto pode acidificar o solo, sendo esta acidificação atribuída às reações de nitrificação da $\mathrm{NH}_{4}^{+}$, à oxidação de sulfitos e à produção de ácidos orgânicos durante a degradação do resíduo. Porém, segundo Scherer e Baldissera (1994), a possibilidade de alteração do pH no solo com a aplicação de esterco líquido de suínos é mínima, principalmente tratando-se de solos altamente tamponados, ainda que os teores de alumínio possam ser diminuídos especialmente pelo incremento de compostos orgânicos de baixo peso molecular.O pH dos lixiviados (Tabela 3) mostrou-se também com tendência ácida, valores quase sempre inferiores a 6,5 e um desvio padrão (DP) máximo de 1,07. Nos lixiviados provenientes dos solos incubados o $\mathrm{pH}$ foi maior do que aquele dos não incubados, isto já era previsto em função da aplicação de $\mathrm{CaCO}_{3}$. Estudos de Luchese, Costa e Souza (2008) mostraram aumento nos valores de $\mathrm{pH}$ até a sexta coleta de lixiviados na quase totalidade dos tratamentos, sendo que os últimos valores corresponderam aos maiores $\mathrm{pH}$ observados, média de 6,09 contra 5,69 obtidos nos tratamentos do primeiro pulso. No presente estudo, os valores de $\mathrm{pH}$ variaram apresentando, em sua maioria, valores menores que os encontrados na primeira coleta, corroborando o autor supracitado.

O N é o nutriente presente em maior concentração no efluente estudado e, portanto, com maior potencial de contaminação em solos sob sua aplicação. Os valores de $\mathrm{NH}_{4}^{+}$(Tabela 4) nos nitossolos aumentaram em função das taxas de aplicação com um coeficiente de variação (CV) máximo de $87 \%$ em $150 \mathrm{~m}^{3}$.ha-1. No ARG INC, a taxa de aplicação $150 \mathrm{~m}^{3} \cdot \mathrm{ha}^{-1}$ apresentou o maior valor de $\mathrm{NH}_{4}^{+}$com $0,40 \mathrm{mg} \cdot \mathrm{L}^{-1}$, porém, também mostrou um maior DP de 0,45 mg. $\mathrm{L}^{-1}$ e CV de $112 \%$.

Pode-se atribuir que o efeito do $\mathrm{NH}_{4}^{+}$nos solos seja devido ao $\Delta \mathrm{pH}$ no qual os valores negativos evidenciam que há predomínio da carga líquida negativa nos solos com textura arenosa sob a influência da água residuária ou não, enquanto que nos solos de textura argilosa predominam cargas positivas (Tabela 3). Segundo Meurer, Rhenheimer e Bissani (2000), a adição de matéria orgânica ou de sais como na adição de fertilizantes, pode deixar o $\Delta \mathrm{pH}$ mais negativo, porque há um aumento do pH em água.

É importante destacar que os solos deste estudo foram coletados em barrancos, portanto sujeitos á perda de nutrientes, como pode ser observado na Tabela 2, em que os teores de nutrientes iniciais foram baixos, principalmente no argissolo. Os valores de $\Delta \mathrm{pH}$ negativos no solo de textura arenosa podem ser mais frequentes devido à maior concentração de matéria orgânica no solo testemunha em relação ao de textura argilosa.

Tabela 3 - pH nos solos e lixiviados.

\begin{tabular}{|c|c|c|c|c|c|c|c|c|c|}
\hline \multirow{2}{*}{ Amostras } & \multirow{2}{*}{$\begin{array}{c}\text { TA } \\
\left(\mathrm{m}^{3} \cdot \mathrm{ha}^{-1}\right)\end{array}$} & \multicolumn{2}{|c|}{ ARE INC } & \multicolumn{2}{|c|}{ ARE } & \multicolumn{2}{|c|}{ ARG INC } & \multicolumn{2}{|c|}{ ARG } \\
\hline & & Média+DP & CV (\%) & Média+DP & CV (\%) & Média_DP & CV (\%) & Média+DP & CV (\%) \\
\hline \multirow{4}{*}{ Solos } & 0 & $4,97 \pm 0,15$ & 3 & $4,28 \pm 0,04$ & 1 & $5,80 \pm 0,08$ & 1 & $5,11 \pm 0,06$ & 1 \\
\hline & 50 & $4,69 \pm 0,12$ & 3 & $4,18 \pm 0,11$ & 3 & $5,83 \pm 0,05$ & 1 & $5,31 \pm 0,18$ & 3 \\
\hline & 100 & $4,68 \pm 0,09$ & 2 & $4,06 \pm 0,03$ & 1 & $5,64 \pm 0,07$ & 1 & $5,48 \pm 0,14$ & 3 \\
\hline & 150 & $4,35 \pm 0,04$ & 1 & $4,04 \pm 0,04$ & 1 & $5,74 \pm 0,08$ & 1 & $5,36 \pm 0,03$ & 1 \\
\hline \multirow{4}{*}{ Primeiro lixiviado } & 0 & $4,92 \pm 0,32$ & 7 & $4,36 \pm 0,20$ & 5 & $6,25 \pm 0,07$ & 4 & $5,10 \pm 0,21$ & 1 \\
\hline & 50 & $4,87 \pm 0,24$ & 5 & $4,41 \pm 0,08$ & 2 & $6,16 \pm 0,06$ & 4 & $5,22 \pm 0,23$ & 1 \\
\hline & 100 & $4,69 \pm 0,19$ & 4 & $4,46 \pm 0,14$ & 3 & $6,07 \pm 0,05$ & 6 & $5,24 \pm 0,31$ & 1 \\
\hline & 150 & $4,74 \pm 0,06$ & 1 & $4,23 \pm 0,13$ & 3 & $5,94 \pm 0,05$ & 3 & $6,40 \pm 0,18$ & 1 \\
\hline \multirow{4}{*}{$\begin{array}{l}\text { Segundo } \\
\text { lixiviado }\end{array}$} & 0 & $6,95 \pm 0,81$ & 12 & $5,23 \pm 0,06$ & 1 & $5,73 \pm 0,22$ & 3 & $5,17 \pm 0,14$ & 4 \\
\hline & 50 & $6,50 \pm 1,07$ & 16 & $5,13 \pm 0,08$ & 2 & $5,93 \pm 0,10$ & 2 & $5,24 \pm 0,12$ & 2 \\
\hline & 100 & $5,66 \pm 0,22$ & 4 & $5,06 \pm 0,16$ & 3 & $6,11 \pm 0,27$ & 4 & $5,39 \pm 0,23$ & 4 \\
\hline & 150 & $5,50 \pm 0,24$ & 4 & $4,76 \pm 0,11$ & 2 & $5,88 \pm 0,18$ & 4 & $5,74 \pm 0,22$ & 3 \\
\hline
\end{tabular}

ARE INC: nitossolo incubado com $\mathrm{CaCO}_{3}$; $\mathrm{ARG} \mathrm{INC:} \mathrm{argissolo} \mathrm{incubados} \mathrm{com} \mathrm{CaCO}_{3}$; $\mathrm{ARE}$ : nitossolo sem aplicação de $\mathrm{CaCO}_{3}$; $\mathrm{ARG}$ argissolo sem aplicação de $\mathrm{CaCO}$; $\mathrm{CV}_{\text {: }} \mathrm{Coeficiente} \mathrm{de}$ variação; DP: desvio padrão. 
Os valores da CTC (Tabela 4) foram baixos e a adição de efluente contribuiu para o seu aumento com maior intensidade nos solos de textura arenosa do que nos de textura argilosa. Nos nitossolos, a maior intensidade do valor da carga líquida negativa faz com que haja maior retenção de cátions. $\mathrm{O} \mathrm{NH}_{4}^{+}$será retido no complexo de troca enquanto que o $\mathrm{NO}_{3}^{-}$, que é um ânion, terá adsorção eletrostática insignificante. Desta forma, o $\mathrm{NO}_{3}$ - tende a permanecer na solução do solo, o que favorecerá a sua lixiviação, sendo influenciada diretamente pelos fatores que determinam o fluxo de água no solo e pela concentração existente na solução.

Segundo Meurer, Rhenheimer e Bissani (2000), a adição de matéria orgânica pode afetar o $\Delta \mathrm{pH}$ do solo. A matéria orgânica pode se ligar a argilominerais do solo, como por exemplo, a caulinita e aos óxidos de ferro, diminuindo as cargas positivas, o que resulta num aumento das cargas negativas. Este efeito não se evidenciou no presente estudo, pois o aumento das doses de efluente pareceu não influenciar muito no decréscimo do $\Delta \mathrm{pH}$ (Tabela 3) e no acréscimo de carbono orgânico do solo (Tabela 5). Esta situação pode ser explicada pelo fato do efluente aplicado ter sido tratado por biodigestão e pelas condições do experimento em que os solos apresentados estão sob as primeiras aplicações de efluente.
Nos solos tratados com resíduos orgânicos, a mineralização do $\mathrm{N}$ além de ser altamente dependente da composição do resíduo e das características químicas e físicas do solo que receberá o resíduo, está diretamente relacionada à qualidade do material orgânico, por exemplo, relação carbono/nitrogênio $(\mathrm{C} / \mathrm{N})$. Nos dejetos de suínos líquidos esta relação normalmente é muito baixa, da ordem de 5/1 (FEIGIN; FEIGENBAUM; LIMONI, 1991) ou até menor do que 1/1. No presente estudo os valores da relação $\mathrm{C} / \mathrm{N}$ foram muito baixos (valor médio de 1,38 ) o que evidencia que a mineralização é muito rápida. Isto provavelmente contribuiu para os valores de DQO apresentados no lixiviado, em que nas maiores taxas (100 e $150 \mathrm{~m}^{3}$.ha-1) podem-se observar maiores valores de matéria orgânica oxidável (Tabela 5).

Em relação ao $\mathrm{NO}_{3}$ - dos solos, os teores se encontraram abaixo do limite de detecção do método adotado para análise (CATALDO et al., 1975). Isto pode ser atribuído aos solos apresentaram-se saturados já que imediatamente após a passagem da água destilada para coleta dos lixiviados, os mesmos foram congelados e armazenados em freezer. Esta saturação pode ter provocado modificações nas propriedades do solo pelo estabelecimento de condições de redução (falta de oxigênio $-\mathrm{O}_{2}$ ).

Segundo Moreira e Siqueira (2002), condições anaeróbias, com restrição de $\mathrm{O}_{2}$ ou com quantidades de compostos orgânicos reduzidos favorecem a desnitrificação, pois os organismos

Tabela 4 - Amônia, $\Delta$ pH e capacidade de troca catiônica nos solos.

\begin{tabular}{|c|c|c|c|c|c|c|c|c|c|}
\hline \multirow{2}{*}{ Parâmetros } & \multirow{2}{*}{$\begin{array}{c}\text { TA } \\
\left(m^{3} \cdot \mathrm{ha}^{-1}\right)\end{array}$} & \multicolumn{2}{|c|}{ ARE INC } & \multicolumn{2}{|c|}{ ARE } & \multicolumn{2}{|c|}{ ARG INC } & \multicolumn{2}{|c|}{ ARG } \\
\hline & & Média+DP & CV (\%) & Média $\pm D P$ & CV (\%) & Média $+D P$ & CV (\%) & Média $+D P$ & CV (\%) \\
\hline \multirow{4}{*}{$\mathrm{NH}_{4}^{+}\left(\mathrm{mg} \cdot \mathrm{L}^{-1}\right)$} & 0 & $0,03 \pm 0,01$ & 24 & $0,03 \pm 0,01$ & 27 & $0,20 \pm 0,10$ & 75 & $0,20 \pm 0,08$ & 69 \\
\hline & 50 & $0,05 \pm 0,02$ & 43 & $0,05 \pm 0,03$ & 52 & $0,08 \pm 0,03$ & 41 & $0,23 \pm 0,10$ & 64 \\
\hline & 100 & $0,03 \pm 0,01$ & 37 & $0,27 \pm 0,10$ & 61 & $0,16 \pm 0,04$ & 26 & $0,20 \pm 0,10$ & 49 \\
\hline & 150 & $0,10 \pm 0,04$ & 87 & $0,22 \pm 0,09$ & 67 & $0,40 \pm 0,45$ & 112 & $0,18 \pm 0,07$ & 40 \\
\hline \multirow{4}{*}{$\Delta \mathrm{pH}$} & 0 & $-0,83 \pm 0,06$ & -7 & $-1,08 \pm 0,13$ & -12 & $0,13 \pm 0,06$ & 43 & $-0,22 \pm 0,10$ & -45 \\
\hline & 50 & $-1,05 \pm 0,19$ & -18 & $-0,89 \pm 0,04$ & -4 & $0,39 \pm 0,01$ & 3 & $0,42 \pm 0,56$ & 134 \\
\hline & 100 & $-0,94 \pm 0,19$ & -20 & $-0,75 \pm 0,16$ & -22 & $0,16 \pm 0,06$ & 36 & $0,05 \pm 0,13$ & 262 \\
\hline & 150 & $-0,97 \pm 0,14$ & -15 & $-0,67 \pm 0,24$ & -36 & $0,37 \pm 0,08$ & 22 & $0,20 \pm 0,12$ & 57 \\
\hline \multirow{4}{*}{$\begin{array}{l}\text { CTC } \\
\left(\mathrm{cmol}_{\mathrm{c}^{\prime}} \cdot \mathrm{dm}^{-3}\right)\end{array}$} & 0 & $3,16 \pm 0,56$ & 17 & $3,17 \pm 0,42$ & 13 & $3,43 \pm 0,29$ & 8 & $4,53 \pm 0,95$ & 20 \\
\hline & 50 & $3,56 \pm 0,64$ & 18 & $4,04 \pm 1,10$ & 27 & $3,84 \pm 0,71$ & 18 & $3,90 \pm 0,56$ & 14 \\
\hline & 100 & $3,60 \pm 0,83$ & 26 & $5,67 \pm 0,96$ & 17 & $3,59 \pm 0,53$ & 14 & $4,12 \pm 0,92$ & 22 \\
\hline & 150 & $4,37 \pm 1,02$ & 23 & $4,53 \pm 0,87$ & 19 & $2,99 \pm 0,21$ & 7 & $3,47 \pm 0,43$ & 12 \\
\hline
\end{tabular}

$\mathrm{NH}_{4}^{+}$: amônia; CTC: capacidade de troca catiônica; DP: desvio padrão; ARE INC: nitossolo incubado com CaCO ${ }_{3}$; ARG INC: argissolo incubados com CaCO ${ }_{3}$; ARE: nitossolo sem aplicação de $\mathrm{CaCO}_{3}$; ARG: argissolo sem aplicação de $\mathrm{CaCO}_{3}$.

Tabela 5 - Carbono orgânico nos solos e demanda química de oxigênio no lixiviado.

\begin{tabular}{|c|c|c|c|c|c|c|c|c|c|}
\hline \multirow{2}{*}{ Parâmetros } & \multirow{2}{*}{$\begin{array}{c}\text { TA } \\
\left(\mathrm{m}^{3} \cdot \mathrm{ha}^{-1}\right)\end{array}$} & \multicolumn{2}{|c|}{ ARE INC } & \multicolumn{2}{|c|}{ ARE } & \multicolumn{2}{|c|}{ ARG INC } & \multicolumn{2}{|c|}{ ARG } \\
\hline & & Média+DP & CV (\%) & Média+DP & CV (\%) & Média+DP & CV (\%) & Média+DP & CV (\%) \\
\hline \multirow{4}{*}{$\begin{array}{l}\text { Carbono } \\
\text { Orgânico } \\
\left(\mathrm{mg}^{-d_{m}^{-3}}\right) \\
\text { Solos }\end{array}$} & 0 & $0,53 \pm 0,06$ & 12 & $0,51 \pm 0,05$ & 10 & $0,38 \pm 0,09$ & 25 & $0,34 \pm 0,02$ & 5 \\
\hline & 50 & $0,48 \pm 0,04$ & 9 & $0,51 \pm 0,01$ & 9 & $0,37 \pm 0,12$ & 39 & $0,32 \pm 0,04$ & 12 \\
\hline & 100 & $0,48 \pm 0,04$ & 9 & $0,52 \pm 0,01$ & 2 & $0,39 \pm 0,09$ & 24 & $0,37 \pm 0,07$ & 17 \\
\hline & 150 & $0,54 \pm 0,04$ & 8 & $0,48 \pm 0,00$ & 1 & $0,34 \pm 0,09$ & 25 & $0,37 \pm 0,03$ & 9 \\
\hline \multirow{4}{*}{$\begin{array}{l}\text { DQO } \\
\left(\mathrm{mg} \cdot \mathrm{L}^{-1} \mathrm{O}_{2}\right) \\
\text { primeiro lixiviado }\end{array}$} & 0 & $6,84 \pm 3,20$ & 47 & $11,86 \pm 2,01$ & 17 & $8,81 \pm 1,36$ & 15 & $7,82 \pm 3,95$ & 51 \\
\hline & 50 & $9,98 \pm 0,57$ & 6 & $6,34 \pm 1,49$ & 24 & $6,44 \pm 2,15$ & 33 & $7,62 \pm 6,62$ & 87 \\
\hline & 100 & $7,08 \pm 1,40$ & 20 & $12,47 \pm 4,85$ & 39 & $7,65 \pm 0,71$ & 9 & $10,55 \pm 5,78$ & 55 \\
\hline & 150 & $7,11 \pm 0,82$ & 12 & $13,28 \pm 6,60$ & 50 & $10,47 \pm 3,94$ & 38 & $12,64 \pm 3,39$ & 27 \\
\hline
\end{tabular}

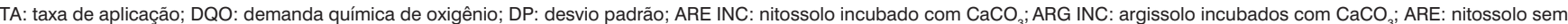
aplicação de $\mathrm{CaCO}_{3}$; ARG: argissolo sem aplicação de $\mathrm{CaCO}_{3}$. 
nitrificadores utilizam os óxidos como receptores terminais de elétrons. De acordo com Scherer e Nesi (2004), perdas por desnitrificação são significantes em solos adubados com estercos animais. Ainda segundo Bissani et al. (2004), o N inorgânico nesta situação se apresenta na forma de $\mathrm{NH}_{4}{ }^{+}$e não ocorre nitrificação. Estes autores evidenciaram que em poucas horas os microorganismos aeróbios consomem todo o oxigênio contido no ar do solo ou dissolvido na solução. O composto oxigenado mais facilmente reduzido é o $\mathrm{NO}_{3}$ - que por desnitrificação se perde por volatilização na forma de $\mathrm{N}_{2}$. Ou seja, na falta de $\mathrm{O}_{2}$ não ocorre nitrificação, porque as bactérias Nitrossomonas e Nitrobacter são organismos exclusivamente aeróbios.

A contaminação $\mathrm{NO}_{3}^{-}$em águas subterrâneas tem tido grande destaque entre os impactos causados em pólos de produção de suínos. Os teores detectados em lençol freático de solos tratados com altas taxas de dejetos líquidos $\left(160 \mathrm{~m}^{3} \cdot \mathrm{ha}^{-1}\right)$ atingem valores dez vezes maiores que os de solos não tratados (PERDOMO \& LIMA, 1998). Pode-se verificar que os valores de $\mathrm{NO}_{3}{ }_{3}^{-}$no primeiro lixiviado para os nitossolos foram muito maiores do que aqueles apresentados nos argissolos (Tabela 6). Isto pode ser atribuído ao $\Delta \mathrm{pH}$ desses solos, como já foi discutido e soma-se também a contribuição da condutividade hidráulica desse nitossolo que é maior em relação ao argissolo.

Em relação ao segundo lixiviado, os valores de $\mathrm{NO}_{3}$ - são menores para os nitossolos se comparados aos primeiros, enquanto que no segundo lixiviado dos argissolos as concentrações de $\mathrm{NO}_{3}$ - foram muito superiores àqueles apresentados no primeiro, principalmente no ARG INC.

Os valores dos lixiviados dos solos incubados foram menores que os não incubados, diferentemente dos resultados de estudos semelhantes realizados por Curtin e Smille (1983) e Azevedo (1991), nos quais houve aumento da concentração de $\mathrm{NO}_{3}{ }^{-}$no lixiviado das colunas com solos com calcário, quando comparado com o mesmo tipo de solo.

Os pequenos teores de $\mathrm{NH}_{4}^{+}$em ambos lixiviados podem ser devido a alguns íons ficarem adsorvidos no complexo de troca, onde predominam cargas negativas (Tabela 6). Por sua vez, em função das cargas negativas apresentadas no $\mathrm{NO}_{3}$ - estes íons são deslocados para a solução, visto que este ânion não tem preferência da adsorção interna dos óxidos de ferro ( $\mathrm{Fe}$ ) e alumínio (Al) do solo, apresentando-se, portanto em altas concentrações nos lixiviados.

De acordo com Lopes e Guidolin (1989), outra explicação para o fato de $\mathrm{O} \mathrm{NO}_{3}^{-}$lixiviar com maior facilidade do que a $\mathrm{NH}_{4}{ }^{+}$seria a carga negativa fraca que o mesmo possui. Assim sendo, ele não é retido no solo, mas permanece como íon livre na água do solo, passível de ser lixiviado através do perfil de certos solos e sob determinadas condições pluviométricas.

Grande parte da população rural que reside nas áreas de exploração de suínos consome água proveniente de poços superficiais. A toxidez do $\mathrm{NO}_{3}^{-}$- em humanos é baixa, mas de 5 a 10\% ingerido na alimentação é convertido a nitrito $\left(\mathrm{NO}_{2}^{-}\right)$na saliva bucal ou por redução gastrointestinal (BOINK \& SPEIJERS, 2001). Segundo estes autores, ao entrar na corrente sanguínea o $\mathrm{NO}_{3}$ - oxida o ferro $\left(\mathrm{Fe}^{+2}\right.$ a $\left.\mathrm{Fe}^{+3}\right)$ da hemoglobina, produzindo a meta-hemoglobina. Esta forma de hemoglobina é inativa e incapaz de transportar o $\mathrm{O}_{2}$ para a respiração normal das células dos tecidos, causando a meta-hemoglobinemia e as células sofrem por asfixia.

O valor máximo permitido pela Portaria $n^{\circ} 2.914 / 2011$ do Ministério da Saúde é de $10 \mathrm{mg} \cdot \mathrm{L}^{-1}$ de $\mathrm{NO}_{3}^{-}$em águas para consumo humano, portanto, nas condições do experimento, os lixiviados dos nitossolos são aqueles com maior potencial de ocasionar impactos negativos ao ambiente em relação a este parâmetro. É importante ressaltar que a intensidade do processo de contaminação depende principalmente da profundidade do lençol freático ou aquífero.

Tabela 6 - Nitrato e amônia nos lixiviados.

\begin{tabular}{|c|c|c|c|c|c|c|c|c|c|}
\hline \multirow{2}{*}{ Parâmetros } & \multirow{2}{*}{$\begin{array}{c}\text { TA } \\
\left(\mathrm{m}^{3} \cdot \mathrm{ha}^{-1}\right)\end{array}$} & \multicolumn{2}{|c|}{ ARE INC } & \multicolumn{2}{|c|}{ ARE } & \multicolumn{2}{|c|}{ ARG INC } & \multicolumn{2}{|c|}{$\mathrm{ARG}$} \\
\hline & & Média+DP & CV (\%) & Média+DP & CV (\%) & Média+DP & CV (\%) & Média+DP & CV (\%) \\
\hline \multirow{4}{*}{$\begin{array}{l}\text { Nitrato } \\
\left(\mathrm{mg} \cdot \mathrm{L}^{-1}\right) \\
\text { primeiro lixiviado }\end{array}$} & 0 & $8,14 \pm 4,77$ & 59 & $28,62 \pm 3,66$ & 13 & $3,49 \pm 0,19$ & 5 & $3,00 \pm 0,08$ & 3 \\
\hline & 50 & $12,57 \pm 6,14$ & 49 & $26,73 \pm 12,10$ & 45 & $3,57 \pm 0,20$ & 6 & $2,92 \pm 0,20$ & 7 \\
\hline & 100 & $23,22 \pm 9,66$ & 42 & $14,36 \pm 2,76$ & 19 & $3,62 \pm 0,13$ & 4 & $2,96 \pm 0,13$ & 47 \\
\hline & 150 & $41,03 \pm 8,78$ & 21 & $27,13 \pm 8,17$ & 30 & $3,62 \pm 0,13$ & 4 & $2,96 \pm 0,47$ & 16 \\
\hline \multirow{4}{*}{$\begin{array}{l}\text { Nitrato } \\
\left(\mathrm{mg} \cdot \mathrm{L}^{-1}\right) \\
\text { segundo lixiviado }\end{array}$} & 0 & $7,74 \pm 0,08$ & 1 & $7,79 \pm 0,08$ & 1 & $4,67 \pm 0,92$ & 20 & $2,17 \pm 0,00$ & 0 \\
\hline & 50 & $7,74 \pm 0,20$ & 3 & $7,74 \pm 0,20$ & 3 & $10,15 \pm 2,36$ & 23 & $2,79 \pm 1,06$ & 38 \\
\hline & 100 & $7,92 \pm 0,08$ & 1 & $7,70 \pm 0,00$ & 0 & $16,86 \pm 9,51$ & 56 & $3,18 \pm 1,06$ & 33 \\
\hline & 150 & $7,79 \pm 0,08$ & 1 & $7,52 \pm 0,15$ & 2 & $37,96 \pm 14,62$ & 39 & $7,17 \pm 2,57$ & 36 \\
\hline \multirow{4}{*}{$\begin{array}{l}\text { Amônia } \\
\left(\mathrm{mg} \cdot \mathrm{L}^{-1}\right) \\
\text { primeiro lixiviado }\end{array}$} & 0 & $0,03 \pm 0,01$ & 24 & $0,06 \pm 0,07$ & 112 & $0,07 \pm 0,07$ & 97 & $0,18 \pm 0,25$ & 141 \\
\hline & 50 & $0,03 \pm 0,00$ & 9 & $0,10 \pm 0,07$ & 77 & $0,02 \pm 0,00$ & 10 & $0,06 \pm 0,04$ & 63 \\
\hline & 100 & $0,05 \pm 0,02$ & 41 & $0,04 \pm 0,03$ & 64 & $0,32 \pm 0,15$ & 46 & $0,05 \pm 0,00$ & 5 \\
\hline & 150 & $0,06 \pm 0,07$ & 122 & $0,24 \pm 0,13$ & 53 & $0,36 \pm 0,09$ & 25 & $0,49 \pm 0,19$ & 40 \\
\hline \multirow{4}{*}{$\begin{array}{l}\text { Amônia } \\
\left(\mathrm{mg} \cdot \mathrm{L}^{-1}\right) \\
\text { segundo lixiviado }\end{array}$} & 0 & $0,09 \pm 0,00$ & 0 & $0,02 \pm 0,00$ & 24 & $0,02 \pm 0,00$ & 14 & $0,02 \pm 0,01$ & 41 \\
\hline & 50 & $0,07 \pm 0,04$ & 56 & $0,04 \pm 0,02$ & 55 & $0,02 \pm 0,00$ & 17 & $0,02 \pm 0,01$ & 25 \\
\hline & 100 & $0,07 \pm 0,04$ & 59 & $0,12 \pm 0,02$ & 18 & $0,11 \pm 0,03$ & 26 & $0,02 \pm 0,01$ & 41 \\
\hline & 150 & $0,09 \pm 0,06$ & 61 & $0,15 \pm 0,02$ & $1 \%$ & $0,10 \pm 0,01$ & 10 & $0,06 \pm 0,01$ & 22 \\
\hline
\end{tabular}

TA: Taxa de aplicação; DP: desvio padrão; ARE INC: nitossolo incubado com $\mathrm{CaCO}_{3}$; ARG INC: argissolo incubados com $\mathrm{CaCO}_{3}$; $\mathrm{ARE}$ nitossolo sem aplicação de CaCO ${ }_{3}$; ARG: argissolo sem aplicação de $\mathrm{CaCO}_{3}$. 
Em relação ao P disponível no solo, pôde-se observar que os valores para o nitossolo foram os mais expressivos e aumentaram em função da taxa de aplicação (Tabela 7). Os baixos valores nos argissolos podem ser atribuídos à forte interação deste nutriente com a superfície das partículas de solos intemperizados. Os principais mecanismos de retenção de $\mathrm{P}$ nos solos, ricos em óxidos, oxi-hidróxidos e hidróxidos de Fe, Al e manganês (Mn), é a adsorção específica através da formação de complexos de esfera interna e a precipitação com Fe e Al (SPOSITO, 1989). Muito embora o teor de P disponível apresentados nos nitossolos fossem altos, nos lixiviados as concentrações apresentadas foram muito pequenas, porém maiores que no solo de textura argilosa incubado.

A aparente contradição entre o conceito de imobilidade do P no solo e sua distribuição no perfil se deve em parte ao fato desse conceito estar relacionado somente à fração inorgânica do $\mathrm{P}$, enquanto que, segundo Cassol et al. (2002), a lixiviação do P no solo ocorre predominantemente em formas orgânicas. Enquanto o P inorgânico tem sua mobilidade controlada pelo tipo e conteúdo de argilominerais e sesquióxidos de ferro e alumínio, o P orgânico apresenta movimentação livre no solo como constituinte de células microbianas e outros coloides orgânicos. Porém, alguns estudos relatam a redistribuição de $\mathrm{P}$ inorgânico ao longo do perfil em condições especiais, como em solos arenosos com baixa capacidade de adsorção, com aplicações massivas de fontes solúveis de $\mathrm{P}$ e submetidos a intensas precipitações (WEAVER et al., 1988a; 1988b).

Segundo Lopes (1989), o P se movimenta pouco na maioria dos solos. Geralmente permanece no local em que foi colocado pela intemperização dos minerais ou pela adubação. Assim, pouco P é perdido por lixiviação, apesar dele se movimentar mais em solos arenosos do que em argilosos. Em estudos semelhantes, Vitti, Boareto e Penteado (1994) perceberam que o P se movimentou mais facilmente com o aumento da dose aplicada no solo, corroborando o presente estudo em que o teor de P no lixiviado elevou-se conforme a taxa de aplicação do efluente.

O fato do adubo na forma orgânica favorecer a concentração de nutrientes na superfície do solo pode contribuir para agravar as perdas dos mesmos através do transporte dos elementos orgânicos do dejeto animal com a enxurrada, uma vez que os elementos orgânicos são os primeiros constituintes do solo a serem removidos pela erosão, em razão de estarem mais concentrados na superfície do solo e por terem menor densidade (CASSOL et al., 2002).

É necessário considerar que, nos solos de origem do basalto da região onde o trabalho foi desenvolvido, este tipo de adubo, na sua grande maioria, é distribuído na superfície do solo, sem incorporação e, pelo menos parte dele é aplicada na época que sucede a colheita da cultura de inverno, antecedente à semeadura da cultura de verão. Por outro lado, na referida região, esta época do ano coincide com a incidência de chuvas de elevada erosividade que podem precipitar sobre solos parcialmente descobertos e parcialmente mobilizados pela operação de semeadura. Em decorrência disso, os danos ambientais podem ser expressivos, em particular nas bacias hidrográficas com rampas muito longas e/ou inclinadas e sem sistema de terraceamento implantado, no caso do transporte de $\mathrm{P}$, uma vez que esse elemento é o principal causador do fenômeno de eutrofização das águas de superfície.

\section{Conclusões}

De acordo com os resultados obtidos, pode-se concluir que o pH do lixiviado encontrou-se abaixo do estabelecido pela Portaria n 2.914/2011 do Ministério da Saúde (BRASIL, 2011) para água destinada ao consumo humano.

$\mathrm{O} \mathrm{NH}_{4}^{+}$nos argissolos obteve valores menores do que aqueles do solo testemunha enquanto que nos nitossolos houve aumento em função das taxas de aplicação.

A relação $\mathrm{C} / \mathrm{N}$ foi baixa evidenciando uma mineralização rápida, contribuindo para os valores de DQO apresentados no lixiviado, em que nas maiores taxas puderam-se verificar maiores valores de matéria orgânica oxidável.

A adição de efluente contribuiu para o aumento da CTC com maior intensidade nos solos de textura arenosa do que nos de textura argilosa.

Os valores de $\mathrm{NO}_{3}$ - no primeiro lixiviado e o P nos nitossolos foram superiores ao do outro solo estudado, elevando-se em função da taxa de aplicação. Além disso, os lixiviados de $\mathrm{NO}_{3}{ }^{-}$no nitossolo são aqueles com maior potencial de ocasionar impactos negativos ao ambiente.

Tabela 7 - Fósforo nos solos e lixiviado.

\begin{tabular}{|c|c|c|c|c|c|c|c|c|c|}
\hline \multirow{2}{*}{ Amostras } & \multirow{2}{*}{$\begin{array}{c}\text { TA } \\
\left(m^{3} \cdot \text { ha }^{-1}\right)\end{array}$} & \multicolumn{2}{|c|}{ ARE INC } & \multicolumn{2}{|c|}{ ARE } & \multicolumn{2}{|c|}{ ARG INC } & \multicolumn{2}{|c|}{ ARG } \\
\hline & & Média+DP & CV (\%) & MédiatDP & CV (\%) & Média+DP & CV (\%) & Média+DP & CV (\%) \\
\hline \multirow{4}{*}{$\begin{array}{l}\text { Solos } \\
\left(\mathrm{mg}^{\left.-\mathrm{dm}^{-3}\right)}\right.\end{array}$} & 0 & $1,92 \pm 1,42$ & 74 & $2,84 \pm 0,44$ & 16 & $0,34 \pm 0,00$ & 0 & $0,63 \pm 0,25$ & 40 \\
\hline & 50 & $4,25 \pm 0,06$ & 16 & $4,26 \pm 0,49$ & 12 & $0,78 \pm 0,00$ & 0 & $0,75 \pm 0,39$ & 52 \\
\hline & 100 & $5,11 \pm 2,04$ & 40 & $9,45 \pm 1,15$ & 12 & $0,95 \pm 0,24$ & 25 & $1,15 \pm 0,39$ & 34 \\
\hline & 150 & $15,91 \pm 2,02$ & 13 & $16,38 \pm 2,64$ & 16 & $0,78 \pm 0,00$ & 0 & $0,56 \pm 0,31$ & 56 \\
\hline \multirow{4}{*}{$\begin{array}{l}\text { Primeiro lixiviado } \\
\left(\mathrm{mg} \cdot \mathrm{L}^{-1}\right)\end{array}$} & 0 & $0,78 \pm 0,00$ & 0 & $1,12 \pm 1,10$ & 98 & $0,34 \pm 0,00$ & 0 & $3,97 \pm 3,28$ & 78 \\
\hline & 50 & $1,12 \pm 0,00$ & 0 & $1,34 \pm 0,31$ & 56 & $0,34 \pm 0,00$ & 0 & $3,23 \pm 0,00$ & 0 \\
\hline & 100 & $3,13 \pm 2,03$ & 65 & $1,90 \pm 0,00$ & 0 & $0,54 \pm 0,00$ & 0 & $3,81 \pm 0,00$ & 0 \\
\hline & 150 & $3,34 \pm 0,00$ & 0 & $3,97 \pm 0,62$ & 16 & $2,33 \pm 0,00$ & 0 & $4,12 \pm 0,00$ & 0 \\
\hline
\end{tabular}

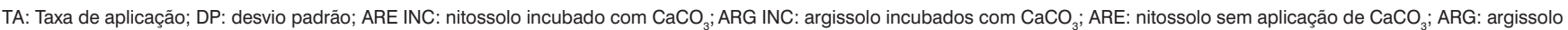
sem aplicação de $\mathrm{CaCO}_{3}$. 


\section{Referências}

AMERICAN PUBLIC HEALTH ASSOCIATION (APHA). (2005) Standard Methods for the Examination of Water and Wastewater. 21st ed. APHA: Washington, D.C.

ASSOCIAÇÃO BRASILEIRA DE NORMAS TÉCNICAS (ABNT). (1999) NBR 14283: Resíduos sólidos: classificação. Rio de Janeiro.

AZEVEDO, M.L.A. (1991) Utilização de estercos de suínos "in natura" em pastagem de capim gordura (Mellinis minutiflora Beauv.). $74 \mathrm{f}$. Dissertação (Mestrado em Solos e Nutrição de Plantas) - Universidade Federal de Viçosa, Viçosa.

BOINK, A. \& SPEIJERS, G. (2001) Helth effect of nitrates and nitrites, a review. Acta Horticulturae, v. 1, n. 563, p. 29-36.

BRASIL. Ministério da Saúde. Portaria n 2.914 de 12 de dezembro de 2011. Dispõe sobre os procedimentos de controle e de vigilância da qualidade da água para consumo humano e seu padrão de potabilidade. Brasília: Ministério da Saúde. Disponível em: <http://portal.saude.gov.br/portal/ arquivos/pdf/portaria_2914_12_12_2011.pdf>. Acesso em: 11 jan. 2013.

BISSANI, C.A.; GIANELLO, C.; TEDESCO, M.J.; CAMARGO, F.A.O. (2004) Fertilidade dos solos e manejo da adubação de culturas. Porto Alegre: Gênesis. 328 p.

CASSOL, E.A.; LEVIEN, R.; ANGHINONI, I.; BADELUCCI, M.P. (2002) Perdas de nutrientes por erosão em diferentes métodos de melhoramento de pastagem nativa no RS. Revista Brasileira de Ciência do Solo, v. 26, n. 3, p. 705-712.

CATALDO, D.A.; HARROON, M.; SCHRADER, L.E.; YOUNGS, V.L. (1975) Rapid colorimetric determination of nitrate in plant tissue by nitration of salicilic acid. Communications in Soil Science and Plant Analysis, v. 6, n. 1, p. $71-80$

CURTIN, D. \& SMILLIE, G.W. (1983) Soil solution composition as affected by liming and incubation. Soil Science Society of American Journal. v. 47, n. 4 , p. $701-707$.

EMPRESA BRASILEIRA DE PESQUISA AGROPECUÁRIA (EMBRAPA). (1999) Manual de análises químicas de solos, plantas e fertilizantes. Brasília: EMBRAPA.

EMPRESA BRASILEIRA DE PESQUISA AGROPECUÁRIA (EMBRAPA) (1997). Manual de métodos de análise de solos. 2 ed. Rio de Janeiro: EMBRAPA

FEIGIN, A.; FEIGENBAUM, S.; LIMONI, H. (1991) Utilization efficiency of nitrogen from sewage effluent and fertilizer applied to corn plants growing in a clay soil. Journal of Environmental Quality, v. 10, p. 284-287.

KONZEN, E.A. (1983) Manejo e utilização dos dejetos de suínos. Concórdia: EMBRAPA-CNPSA. $32 \mathrm{p}$

LOPES, A.S. (1989) Manual de fertilidade do solo. São Paulo: ANDA/ POTAFOS. $153 \mathrm{p}$.

LOPES, A.S. \& GUIDOLIN. J.A. (1989) Interpretação de análise do solo: conceitos e aplicações. 2 ed. São Paulo: ANDA. 64 p.
LUCHESE, A.V.; COSTA, A.C.S.; SOUZA, I.G.J. (2008) Lixiviação de íons após a aplicação de resíduos orgânicos de uma indústria farmoquímica. Revista Brasileira de Engenharia Agrícola e Ambiental, v. 12, n. 2 , p. 189-199.

MEURER, E.J.; RHENHEIMER, D.; BISSANI, C.A. (2000) Fundamentos de química do solo. Porto Alegre: Gênesis. $174 \mathrm{p}$.

MOREIRA, F.M.S. \& SIQUEIRA, J.O. (2002) Microbiologia e bioquímica do solo, Lavras: UFLA. $626 \mathrm{p}$.

PERDOMO, C.C. \& LIMA, G.J.M.M. (1998) Suinocultura intensiva: consideração sobre a questão dos dejetos e o meio ambiente. Concórdia: EMBRAPA - CNPSA. 223 p.

PREVEDELLO, C.L. (1996) Física do solo com problemas resolvidos. Curitiba: Salesward-Discovery. $446 \mathrm{p}$

SCHERER, E.E. \& BALDISSERA, I.T. (1994) Aproveitamento dos dejetos de suínos como fertilizante In: DIA DE CAMPO SOBRE MANEJO DE UTILIZAÇÃO DE DEJETOS SUÍNOS, 1994. Concórdia. Anais... Concórdia: EMBRAPA-CNPSA, p. 33-38

SCHERER, E.E. \& NESI, C.N. (2004) Alterações nas propriedades químicas dos solos em áreas intensivamente adubadas com dejetos suínos. In: REUNIÃO BRASILEIRA DE FERTILIDADE DO SOLO E NUTRIÇÃO DE PLANTAS, 26., 2004. Lajes. Anais... Lajes: SBCS/ UDESC, 2004

SEGANFREDO, M.A. (2000) A questão ambiental na utilização de dejetos de suínos como fertilizante do solo. Concórdia: EMBRAPA/ Circular Técnica, 22. 37 p.

SIMONETE, M.A. (2001) Alterações nas propriedades químicas de um argissolo adubado com lodo de esgoto e desenvolvimento e acúmulo de nutrientes em plantas de milho. Piracicaba. $89 \mathrm{f}$. Tese (Doutorado em Solos e Nutrição Vegetal) - Escola Superior de Agricultura "Luiz de Queiroz", Universidade de São Paulo, Piracicaba.

SPOSITO, G. (1989) The surface chemistry of soil. New York: Oxford University Press. 234 p.

TEDESCO, M.J.; GIANELLO, C.; BISSANI, C.A.; BOHNEN, H.; VOLKWEISS, S.J. (1995) Análise de solo, plantas e outros materiais. 2 ed. Porto Alegre: UFRS. $174 \mathrm{p}$

VITTI, G.C.; BOARETO, A.E.; PENTEADO, S.R. (1994) Fertilizantes e fertirrigação. In: VITTI, G.C. \& BOARETO, A.E. Fertilizantes fluidos. Piracicaba: Potafos. p. 261-281

WEAVER, D.M.; RITCHIE, G.S.P.; ANDERSON, G.C; DEELEY, D.M. (1988a) Phosphorus leaching in sandy soils. I. Short-term effects of fertilizer applications and enviromental conditions. Australian Journal of Soil Research, v. 26, p. $177-190$

WEAVER, D.M.; RITCHIE, G.S.P.; ANDERSON, G.C; DEELEY, D.M. (1988b) Phosphorus leaching in sandy soils. II. Laboratory studies of the long-term effects of phosphorus source. Australian Journal of Soil Research, v. 26, p. $191-200$ 